AperTO - Archivio Istituzionale Open Access dell'Università di Torino

Negativization of viremia prior to liver transplant reduces early allograft dysfunction in hepatitis C recipients

This is a pre print version of the following article:

Original Citation:

Availability:

This version is available http://hdl.handle.net/2318/1644432

since 2018-11-09T11:52:57Z

Published version:

DOI:10.1002/lt.24772

Terms of use:

Open Access

Anyone can freely access the full text of works made available as "Open Access". Works made available under a Creative Commons license can be used according to the terms and conditions of said license. Use of all other works requires consent of the right holder (author or publisher) if not exempted from copyright protection by the applicable law. 


\title{
NEGATIVIZATION OF VIREMIA PRIOR TO LIVER TRANSPLANT REDUCES \\ EARLY ALLOGRAFT DYSFUNCTION IN HEPATITIS C RECIPIENTS
}

\author{
Silvia Martini ${ }^{1}$, Francesco Tandoi ${ }^{2}$, Lodovico Terzi di Bergamo ${ }^{1}$, Silvia Strona ${ }^{1}$, \\ Bruna Lavezzo 3 , Marco Sacco ${ }^{1}$, Francesca Maione², Federica Gonella², \\ Dominic Dell Olio ${ }^{4}$, Mauro Salizzoni², Giorgio Maria Saracco ${ }^{1}$, Renato Romagnoli \\ ${ }^{1}$ Gastrohepatology Unit \\ ${ }^{2}$ Liver Transplant Center, General Surgery $2 \mathrm{U}$ \\ ${ }^{3}$ Anesthesia and Intensive Care Unit 3 \\ ${ }^{4}$ Regional Transplant Center, Piedmont \\ AOU Città della Salute e della Scienza di Torino, University of Torino, Turin, Italy
}

Key words: direct-acting antivirals, 90-day survival, early graft dysfunction, timing of antiHCV therapy, HCV RNA status 


\section{List of abbreviations}

$\mathrm{Cl}$, confidence interval; DAA, direct-acting antiviral agent; EAD, early allograft dysfunction; HBcAb, hepatitis B core antibody; HCC, hepatocellular carcinoma; HCV, hepatitis C virus; LT, liver transplantation; MELD, Model for End-stage Liver Disease; OR, odds ratio.

\section{Financial Support}

The Authors did not receive any grant or financial support for this work.

\section{Conflicts of interest}

SM is a Regional Advisory Board member for Gilead, FT is an Advisory Board member for Biotest, GMS is an Advisory Board member for AbbVie, Gilead and MSD and RR is an Advisory Board member for Biotest. The other Authors who have taken part in this study declared no conflict of interest.

\section{Contact information}

Silvia Martini, MD

Gastrohepatology Unit

AOU Città della Salute e della Scienza di Torino

Corso Bramante 88 - 10126 Turin, Italy

Phone: +39 011 6335928; fax: +390116334014

E-mail address: smartini@cittadellasalute.to.it 


\section{ABSTRACT (274/274)}

Whereas early allograft dysfunction (EAD) negatively impacts on survival from the first months following liver transplantation (LT), direct-acting antivirals (DAAs) have revolutionized HCV therapy. In HCV-positive recipients, we investigated the EAD definition best predicting 90-day graft loss and identified EAD risk factors.

From 11-2002 to 06-2016, $603 \mathrm{HCV}$-positive patients (hepatocellular carcinoma 53\%) underwent a first LT with HCV-negative donors. Median recipient MELD score 15, median donor age 63 years. At LT, 77 (12.8\%) patients were HCV RNA negative; negativization was achieved and maintained by pre-LT antiviral therapy (61 patients) or preLT+preemptive post-LT course (16 patients); 60 (78\%) patients received DAAs and 17 (22\%) interferon. We compared three different EAD definitions: a) bilirubin $\geq 10 \mathrm{mg} / \mathrm{dL}$ or INR $\geq 1.6$ on day 7 post-LT or AST or ALT>2000 IU/L within 7 days of LT; b) bilirubin $>10$ $\mathrm{mg} / \mathrm{dL}$ on days 2 to 7 post-LT; c) MELD $\geq 19$ on day 5 post-LT.

EAD defined by MELD $\geq 19$ on day 5 post-LT had the lowest negative (0.1) and the highest positive (1.9) likelihood ratio to predict 90 -day graft loss. At 90 days post-LT, $9.2 \%$ of recipients with EAD lost their graft as opposed to $0.7 \%$ of those without $E A D(p<0.001)$. At multivariate analysis considering variables available at $L T, M E L D$ at $L T>25(O R=7.4)$ or 15-25 (OR=3.24), graft macrovesicular steatosis $\geq 30 \%$ (OR=6.7), HCV RNA positive at LT $(\mathrm{OR}=2.7)$, donor age $>70$ years $(\mathrm{OR}=2.0)$, earlier $\mathrm{LT}$ era $(\mathrm{OR}=1.8)$, cold ischemia time $\geq 8$ hours $(O R=1.8)$ were significant risk factors for $E A D$.

Conclusions. In HCV-positive patients, MELD $\geq 19$ on day 5 post-LT best predicts 90 -day graft loss. Preventing graft infection by pre/peri-LT antiviral therapy reduces EAD incidence. This could prove to be most beneficial in high MELD patients and recipients of suboptimal grafts. 


\section{INTRODUCTION}

Hepatitis $\mathrm{C}$ virus $(\mathrm{HCV})$ is the main cause of cirrhosis and hepatocellular carcinoma (HCC) and still represents the most common indication for liver transplantation (LT) in Europe and United States (1). Although infection recurs almost universally in patients who are viremic at the time of LT (2), the recent advent of safe and effective direct-acting antiviral agents (DAAs) has revolutionized HCV therapy. Yet, the debate about the best time to treat the infection in the transplant setting is still open (3-5). On one hand, pre-LT eradication is aimed at improving liver disease which may lead to the delisting of some patients (an appropriate strategy in the ongoing context of organ shortage) (6), and at preventing graft infection thus facilitating post-LT management (7). This approach could be particularly appropriate in areas where, in the last decade, median donor age has come to exceed 60 years, thus leading to a more severe HCV recurrence (8). On the other hand, unpredictable waiting time, antiviral therapy duration, risk of patient death and/or tumour progression on the list, and higher rates of sustained virological response in transplant recipients compared with decompensated cirrhotic patients, incline clinicians to treat infection after LT, generally starting after three months from LT, as suggested in the last update of the European Association for the Study of the Liver recommendations (3). It is unlikely that clinical trials will be feasible to prospectively compare these two different approaches, as they would have to recruit a prohibitively large number of patients and extend over an exceedingly long time (5).

In the last two decades the transplant community has increased its efforts to expand the donor pool by using so-called 'extended criteria donors' in order to circumvent donor organ shortage. A consequence of this policy has been an increased incidence of poor graft function immediately after transplant (9). Early allograft dysfunction (EAD) in LT recipients adversely affects graft and patient survival, starting from the very first months after LT, and 
may lead to extrahepatic organ dysfunction, especially kidney impairment (10). Multiple definitions of EAD have been proposed in order to identify LT recipients who are at risk for graft loss within 90-180 days of transplant, such as: i) Olthoff's definition: total bilirubin level $\geq 10 \mathrm{mg} / \mathrm{dL}$ or INR $\geq 1.6$ on postoperative day 7 or AST or ALT level $>2000 \mathrm{IU} / \mathrm{L}$ within the first 7 days (11); ii) Deschênes's definition: peak total bilirubin level $>10 \mathrm{mg} / \mathrm{dL}$ on postoperative days 2 to 7 (12); iii) Wagener's definition: Model for End-stage Liver Disease (MELD) score on postoperative day 5 higher than 18.9 (13).

Donor age $>45$ years, recipient MELD score at LT, donor body mass index, degree of graft macrovesicular steatosis, cold ischemia time and HCV infection have been reported as significant risk factors for $\operatorname{EAD}(11,14,15)$, but until now no study has either focused solely on the HCV-positive population, or, more relevantly, has investigated the potential impact of HCV RNA status at transplant on EAD incidence.

This retrospective single-center study was performed on a series of HCV-positive first LT recipients, with the following objectives: i) to establish the EAD definition best predicting graft loss within 90 days of transplant; ii) to assess EAD impact on 90-day graft and patient survival; iii) to identify independent risk factors for EAD in this population.

We intended herewith to generate new data which could be applied to optimize early outcomes of HCV-positive LT recipients in the current era of extraordinarily effective DAAs but of persisting organ shortage.

\section{MATERIALS AND METHODS}

\section{Study population}

From November 2002 to June 2016, 1,706 first LTs were performed at the Liver Transplant Center of Turin, Italy. In this study, we enrolled 603 consecutive adult HCV- 
positive cirrhotic patients who underwent a first LT with grafts from HCV-negative, brain dead heart-beating donors. All livers were preserved with conventional static cold storage. Informed consent was signed by all patients upon entering the waiting list. Due to the retrospective design, no specific approval was sought from the Local Institutional Ethics Committee. By Italian law, Regional Transplantation Centers are the custodians of donor/recipient biomedical data also for research purposes. All study procedures complied with the ethical standards of the 2000 Declaration of Helsinki and the Declaration of Istanbul 2008.

\section{Data collection}

Variables collected in the study population and in their donors are shown in Table 1. The pattern and degree of fatty infiltration of the graft were assessed on liver biopsies which were routinely obtained at the time of transplant surgery, before closing the abdomen.

Total bilirubin, INR, AST, ALT, serum creatinine were analyzed at $L T$ and daily after surgery, up to day 7 .

Laboratory MELD was calculated at LT and on post-transplant day 5.

Mortality or re-transplantation within 90 days were recorded and survival data were collected up to $31^{\text {st }}$ December 2016.

\section{HCV testing}

Antibodies to HCV were detected by the Architect assay (Abbott Laboratories, Abbott Park, IL). HCV RNA was detected until April 2007 by signal amplification Branched-DNA test (Versant ${ }^{\circledR}$ HCV version 3.0, Bayer Diagnostic Corporation, Tarrytown, NY, US, range of quantitation $615-7.7 \times 10^{6} \mathrm{IU} / \mathrm{mL}$ ); after April 2007 by the automated high-sensitivity system COBAS AmpliPrep ${ }^{\circledR} /$ COBAS TaqMan ${ }^{\circledR}$ HCV Version 1 (Roche Molecular Systems Inc, 
range of quantitation $43-6.9 \times 10^{7} \mathrm{IU} / \mathrm{mL}$ ); after October 2012, by the Version 2 of the AmpliPrep ${ }^{\circledR} /$ COBAS TaqMan ${ }^{\circledR} \mathrm{HCV}$ test (range of quantitation $15-1 \times 10^{8} \mathrm{IU} / \mathrm{mL}$ ).

\section{Clinical protocol}

Immunosuppression was based on calcineurin inhibitors (cyclosporine or tacrolimus), antimetabolites and steroids (tapered to suspension in 6 months). Moderate/severe acute rejection episodes were treated with high-dose methylprednisolone boluses on three consecutive days; monoclonal anti-CD3 antibodies were used in steroid-resistant rejections.

Anti-HCV therapy before LT was based until May 2014 on ribavirin and peginterferon- $\alpha \pm$ first generation protease inhibitors and it was applicable only in few well compensated cirrhotic patients affected by HCC. Since June 2014, DAAs plus ribavirin were used in all patients listed for LT with a MELD score below 25 , a creatinine clearance $\geq 30 \mathrm{~mL} / \mathrm{min}$ and an expected time on the waiting list of at least 3 months. Patients who received DAAs before LT and were HCV RNA negative for less than 30 days at the time of LT, continued antiviral therapy immediately after LT for at least 12 weeks, in order to consolidate HCV RNA negativization $(16,17)$.

\section{Study outcome measure}

Graft loss within 90 days of transplant, defined as mortality or re-transplantation, was the study outcome measure.

\section{Study endpoint and objectives}

EAD was the study endpoint and it was investigated with three objectives:

I) to establish the EAD definition best predicting graft loss within 90 days of transplant.

For this purpose, we compared three previously published EAD definitions: a) total bilirubin 
$\geq 10 \mathrm{mg} / \mathrm{dL}$ or INR $\geq 1.6$ on postoperative day 7 or AST or ALT $>2000 \mathrm{IU} / \mathrm{L}$ within the first seven days (11); b) peak total bilirubin $>10 \mathrm{mg} / \mathrm{dL}$ on postoperative days 2 to 7 (12); c) MELD score $>18.9$ on postoperative day 5 (13);

II) to assess the extent of EAD impact on 90-day graft and patient survival;

III) to identify EAD independent risk factors.

\section{Statistical analysis}

Categorical variables were reported as number (\%) and quantitative variables were shown as median $\left(25^{\text {th }}-75^{\text {th }}\right.$ percentiles $)$.

Receiver operating characteristic curve was plotted and the point on the curve closest to the upper left corner was considered the best cut-off value of MELD score on posttransplant day 5 best predicting 90-day graft loss.

Positive and negative likelihood ratios were calculated for each EAD definition. Kaplan-Meier analysis was performed to evaluate the effect of EAD on graft survival, and survival curves were compared using the log-rank test.

Univariate analyses were carried out using chi-square test for categorical variables and Mann-Whitney test for continuous variables.

To obtain a parsimonious set of EAD predictors, recipient and donor variables available at LT were selected based on the background knowledge. The variables were fitted into a logistic regression model and a stepwise backward elimination was used. Odds ratio (OR) and $95 \%$ confidence interval $(\mathrm{Cl})$ were reported.

Data elaboration was performed using $\mathrm{R}$ software (version 3.3.1).

\section{RESULTS}

Of the 603 enrolled patients, a majority were males (81\%), 10.2\% were affected by HCV genotype $1 \mathrm{a}, 62.2 \% 1 \mathrm{~b}, 7.4 \% 2,13.9 \% 3$ and $6.3 \% 4$. They were affected by HCC in 
$53.4 \%$ of cases and their median MELD score at LT was 15 . Seventy-seven patients (9.5\% HCV genotype 1a; 56.8\% 1b, 5.4\% 2, 21.6\% 3 and 6.7\% 4) were HCV RNA negative at LT: $17(22.1 \%)$ received peginterferon- $\alpha$ and ribavirin and $60(77.9 \%)$ received DAAs plus ribavirin before LT. Sixteen patients bridged DAAs from pre- to post-LT for at least 12 weeks to maintain HCV RNA negativization. Two patients relapsed at week 4 after LT: the first one affected by HCV genotype $1 b$, was treated until LT with peginterferon- $\alpha$ plus ribavirin for 24 weeks and the second one affected by genotype 4, received sofosbuvir plus ribavirin for 141 days before LT; both patients were HCV RNA negative at LT by at least 30 days and stopped antiviral therapy at LT. The median donor age was 63 years with one third of the donors being older than 70 . The median donor risk index was 1.83 and $3 \%$ of the grafts showed a macrovesicular steatosis $\geq 30 \%$ (Table 1). Table $\mathbf{S 1}$ shows the clinical and demographic characteristics of donors and recipients according to HCC diagnosis.

Fig. S1 depicts the trend of bilirubin, INR and creatinine during the first 7 days after LT. The rate of primary non function was $1 \%(6 / 603)$. Two patients lost their graft on day 1 , two on day 4, one on day 5 and one on day 7 after surgery. They all underwent re-LT. According to the receiver operating characteristic curve, the best cut-off of MELD score on post-transplant day 5 to predict 90 -day graft loss was 18.5 (area under the curve $0.8,95 \%$ Cl: 0.7-0.8) (Fig. S2).

\section{Comparison of different EAD definitions}

We evaluated the risk of EAD occurrence according to three different definitions:

a) Total bilirubin $\geq 10 \mathrm{mg} / \mathrm{dL}$ or INR $\geq 1.6$ on postoperative day 7 or AST or ALT $>2000 \mathrm{IU} / \mathrm{L}$ within the first 7 days.

328 out of 603 (54.4\%) patients satisfied this definition. All the six patients who lost their graft within day 7 satisfied the criterion of conspicuously raised transaminase. 
b) Peak total bilirubin $>10 \mathrm{mg} / \mathrm{dL}$ on postoperative days 2 to 7 .

308 out of 601 patients (51.2\%) satisfied this definition. The four patients who lost their graft between days 4 and 7 also satisfied this definition.

c) MELD $\geq 19$ on post-transplant day 5 .

314 out of 599 (52.4\%) patients satisfied this definition. The 2 patients who lost their graft on days 5 and 7 showed on day 5 a MELD score of 41 and 32, respectively. Of the three definitions, a MELD score $\geq 19$ on day 5 after surgery showed the highest positive likelihood ratio (1.9) and the lowest negative likelihood ratio (0.1) to predict 90-day graft loss (Table 2). This EAD definition satisfied the first study objective and was used for subsequent analyses.

\section{Ninety-day graft and patient survival}

Thirty-five out of 603 (5.8\%) patients lost their graft within 90 days after surgery due to graft complications (6 primary non function, 12 delayed non function, 2 hepatic artery thrombosis, 1 biliary complication, 1 acute rejection, 1 hepatic veno-occlusive disease), infection and multi organ failure (9 patients), HCV recurrence (2 patients), cardiac failure (1 patient). Twenty patients (3.3\%) with graft complications underwent re-LT, while 18 patients $(3.0 \%)$ died within 90 days of LT (Table 1).

The occurrence of EAD significantly worsened the 90 -day graft $(90.8 \%$ vs. $99.3 \%$, $p<0.001)$ and patient $(94.9 \%$ vs. $99.6 \%, p<0.001)$ survival rates (Fig. 1A and 1B).

\section{Risk factors for EAD}

Table 3 shows the association of clinical factors with EAD at univariate analysis.

The rates of $\mathrm{HCC}$ and of HCV RNA negativity were significantly higher in the non-EAD group. On the other hand, MELD at LT, donor age $x$ recipient MELD, donor risk index, cold 
ischemia time and in-hospital stay were significantly reduced in the non-EAD group compared with the EAD one.

To account for the changes in transplant care and performance which occurred over time, we compared the first (Nov 2002 - Mar 2009; n=300) with the second (Apr 2009 - Jun 2016; $n=299$ ) half of patients enrolled in the study. EAD rate decreased from $61.3 \%$ in the earlier era to $43.5 \%$ in the more recent one $(p<0.001)$. The latter era was characterized by a significant increased donor age and incidence of graft macrovesicular steatosis $\geq 30 \%$, whilst the cold ischemia time duration and the proportion of hepatitis B core antibody positive grafts were lower and the rates of HCC and HCV RNA negative patients at LT were higher (Table S2).

Table 4 depicts as HCV RNA negative patients compared with positive ones, showing a significantly higher rate of HCC, and a lower MELD score at LT. Median donor age and the rate of graft macrovesicular steatosis $\geq 30 \%$ were significantly higher in the negative group. Table 5 summarizes the results of the multivariate logistic regression performed on a set of recipient and donor features available at LT. All variables significantly associated with EAD at univariate analysis, were included, except for donor risk index which was replaced by donor age due to its well-known detrimental effect on LT outcomes in HCV positive recipients. We forced into the analysis also graft macrovesicular steatosis $\geq 30 \%$, because we observed that four such livers were lost within day 4 post-transplant and were consequently missed by EAD defined as MELD $\geq 19$ on day 5 .

A MELD score at $L T>25(\mathrm{OR}=7.4)$, graft macrovesicular steatosis $\geq 30 \%(\mathrm{OR}=6.7)$, a MELD score al LT between 15 and 25 (OR=3.2), HCV RNA positivity at LT (OR=2.7), donor age $>70$ years $(O R=2.0)$, earlier transplant era $(O R=1.8)$ and a cold ischemia time $\geq 8$ hours $(\mathrm{OR}=1.8)$ resulted as independent predictors of $E A D$.

HCV RNA was an independent predictor of EAD also when the analysis was restricted to the more recent era $(\mathrm{OR}=2.7)$ (Table S3). 
In the 193 patients who received a liver graft older than 70 years, EAD occurred in $61.5 \%$ (99/161) of HCV RNA positive as opposed to $21.9 \%$ (7/32) of HCV RNA negative recipients $(p<0.001)$.

\section{DISCUSSION}

We studied a series of more than six hundred HCV-positive recipients consecutively transplanted from HCV-negative donors and found a significant impact of HCV RNA status at transplant on the incidence of early graft dysfunction.

The advent of DAAs has revolutionized anti-HCV therapy, especially in the LT setting. Indeed, their remarkably good safety profile currently allows to treat patients either before or after LT, so that a heated controversy on the optimal timing for treatment is going on (35). According to a recent decision analytical simulation model of 10,000 patients with Child $B$ and $C$ cirrhosis, treatment before LT seems to be the most cost-effective strategy for patients with decompensated cirrhosis and MELD >13 (18). Furthermore, a European multicenter study showed that DAAs may lead to a remarkable clinical improvement and organ salvage because $19.2 \%$ of the patients treated while on the transplant waiting list were delisted at 60 weeks from the beginning of antiviral therapy (6). Finally, prevention of graft HCV infection simplifies post-LT patient management. Nevertheless, lower rates of virological response in decompensated cirrhotics compared with post-LT recipients and unpredictable waiting time on the LT list can lead clinicians to prefer the post-LT approach, especially for patients with MELD $>18-20$, where data on the efficacy of the new treatments are scanty (19-23). Furthermore, mindful that HCV RNA levels fall sharply at $\mathrm{LT}$, after removal of the liver, the results of a very short pre-emptive antiviral strategy have been recently published. Sixteen patients received sofosbuvir plus ledipasvir one day before and 4 weeks after LT: $33 \%$ of the patients showed an HCV RNA inferior to 15 $\mathrm{IU} / \mathrm{mL}$ on day seven after $\mathrm{LT}$ and the rate of SVR12 was $88 \%(24)$. 
At present, to meet the growing $L T$ demand and the persistent organ shortage, the transplant community is using more and more suboptimal grafts, which are associated with an increased risk of initial poor function and early graft failure. For this reason, in this exciting era of powerful DAAs, we focused on the HCV-positive recipients and investigated whether avoiding HCV re-infection at the time of reperfusion could have beneficial effects on the early functional recovery of the graft. With this aim we studied EAD, a well-known predictor of early graft loss in the transplant population (11-13).

We compared three different, previously established, EAD definitions: 1) Olthoff et al, which considers acute hepatocyte injury (high level of transaminases during the first week), cholestasis and coagulopathy at one week from LT;2) Deschênes et al, which is based on bilirubin level during days 2 to 7 after LT; 3) Wagener et al, which uses the MELD score on day 5 post-LT, expressing graft function and postoperative complications such as infections often associated to renal failure.

More than half of our HCV patients experienced EAD by every definition used, against a significantly lower rate in our non-HCV patients (around $45 \%$, unpublished data). Exclusive HCV etiology and high donor risk index in this study cohort can explain an higher rate of EAD than that reported in other cohorts (which enrolled patients with end-stage liver disease of any etiology); nevertheless our patients showed good 90-day graft and patient survival rates $(11,13,14)$. Similarly to what reported in Wagener's paper (13) on 572 LT recipients (half of them being infected by HCV), we found that a MELD score $\geq 19$ on day 5 post-transplant allowed the best prediction of 90 -day graft loss. Nearly $10 \%$ of EAD patients in our cohort and $17 \%$ in the American one lost their graft within 90 days of transplantation, against $0.7 \%$ and $2 \%$, respectively, of non-EAD patients.

Looking at predictors of EAD in our cohort, MELD score at LT, moderate/severe macrovesicular steatosis and advanced donor age exerted a negative impact, as expected. In addition, we confirmed a protective effect of a cold ischemia time shorter than 8 hours, an 
expedient increasingly adopted by the surgical teams in the more recent years in response to an older donor age. Yet, the most intriguing finding of our study was the significantly and substantially reduced odds ratio for EAD in patients who were HCV RNA negative at LT; this finding was confirmed also when the analysis was restricted to the recent era. Notably, HCV RNA negative patients, compared with positive ones, showed a significantly higher rate of $\mathrm{HCC}$, and as a consequence, a lower MELD score at LT; on the other hand median donor age and the rate of graft macrovesicular steatosis $\geq 30 \%$ were significantly higher in the negative group.

Ischemia/reperfusion injury is recognized as the main culprit of initial poor graft function; it causes the infiltration of polymorphonuclear and T cells, activation of endothelial and Kupffer cells and formation of reactive oxygen species, all leading to hepatocyte injury through inflammation and cytotoxicity (25). Garcia-Retortillo et al (26) published 15 years ago a detailed study on early post-LT HCV kinetics. They showed in 20 patients that HCV RNA circulating levels decrease not only during the anhepatic phase, but also during the first 12 to 24 hours, presumably as a consequence of an uptake of the virus by the hepatocytes and/or the hepatic reticuloendothelial system; furthermore 12 of the 13 patients who were on steroid immunosuppression experienced a persistent increase in HCV RNA in the first week. Likewise, Fukumoto et al (27) showed in 8 of 9 patients who received steroids, azathioprine and calcineurin-inhibitor, that HCV RNA levels increased after the second postoperative day, probably as expression of active viral synthesis, the immunosuppression regimen being the most important determinant of early viral kinetics (28).

Even if sequential histological evaluations were not available in the first days after LT in our patients, we can speculate that the uptake and replication of the virus in the hepatocytes immediately after LT, could interfere with the physiological process of regeneration and functional recovery that normally follows ischemia-reperfusion injury. 
Lastly, it should be noted that the very low EAD incidence that we recorded in HCV RNA negative recipients of grafts older than 70 years provides a new argument against the previously recommended judicious use of advanced age donors in HCV recipients (29). In this fashion, pre or peri-LT viral eradication could not only improve early LT outcomes but also increase LT opportunities for HCV-positive candidates, especially in countries mostly relying on elderly donors.

Although more data on the safety and efficacy of DAAs in severely decompensated patients are eagerly awaited, our findings evidence a so far unrecognized benefit of preventing graft re-infection, thus giving new importance to the transplant hepatologists' attempt at achieving HCV RNA negativization before transplant even in very sick patients. We acknowledge that this retrospective single-center study is limited by the long time needed to recruit an adequate number of patients and the possible effects of changes in transplant care and performance occurring over time. For this reason, we stratified our data for the transplant era, comparing the first with the second half of the study period when the EAD rate was significantly reduced despite a worse donor risk profile. In a multivariate analysis, as expected, the earlier transplant era emerged as an independent predictor of EAD, but this did not invalidate the significant role of the recipient HCV RNA positivity as an EAD risk factor.

In conclusion, HCV-positive recipients presenting a MELD score $\geq 19$ on day 5 post-LT are at increased risk of graft loss within 90 days of transplantation. Our data suggest that negativization of viremia by pre-LT antiviral therapy not only prevents graft infection at reperfusion, but also reduces EAD incidence. This therapeutic strategy should be further investigated for its potential to improve early survival, especially in high MELD patients and in recipients of grafts with suboptimal quality due to macrosteatosis or advanced donor age. 


\section{FIGURE LEGEND}

Figure 1. Ninety-day graft $(A)$ and patient $(B)$ survival in $E A D(n=314)$ vs non-EAD

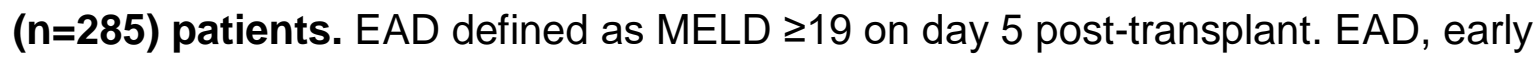
allograft dysfunction; MELD, Model for End-stage Liver Disease. 


\section{REFERENCES}

1. Lavanchy D. Evolving epidemiology of hepatitis C virus. Clin Microbiol Infect $2011 ; 17: 107-115$.

2. Terrault NA. Liver transplantation in the setting of chronic HCV. Best Pract Res Clin Gastroenterol 2012;26:531-548.

3. European Association for the Study of the Liver. EASL recommendations on treatment of hepatitis C 2016. J Hepatol 2017;66:153-194.

4. Bunchorntavakul $\mathrm{C}$ and Reddy KR. Treat chronic hepatitis $\mathrm{C}$ virus infection in decompensated cirrhosis - pre- or post-liver transplantation? The ironic conundrum in the era of effective and well-tolerated therapy. J Viral Hepat 2016;23:408-418.

5. Chhatwal J, Samur S, Kues B, Ayer T, Roberts MS, Kanwal F, et al. Optimal timing of hepatitis $C$ treatment for patients on the liver transplant waiting list. Hepatology 2016, doi:10.1002/hep.28926 [Epub ahead of print].

6. Belli LS, Berenguer M, Cortesi PA, Strazzabosco M, Rockenschaub SR, Martini S, et al. Delisting of liver transplant candidate with chronic hepatitis $\mathrm{C}$ after viral eradication: a European study. J Hepatol 2016;65:524-531.

7. Aghemo A, Donato MF. Sofosbuvir treatment in the pre and post liver transplantation phase: the sooner, the better. Gastroenterology 2015;148:13-16.

8. Martini S, Sacco M, Strona S, Arese D, Tandoi F, Dell Olio D, et al. Impact of viral eradication with sofosbuvir-based therapy on the outcome of post-transplant hepatitis C with severe fibrosis. Liver Int 2017;37(1):62-70.

9. Briceño J, Ciria R, de la Mata M, Rufián S, López-Cillero P. Prediction of graft dysfunction based on extended criteria donors in the model for end-stage liver disease era. Transplantation 2010;90:530-539. 
10. Wadei HM, Lee DD, Croome KP, Mai ML, Golan E, Brotman R, et al. Early allograft dysfunction after liver transplantation is associated with short- and long-term kidney function impairment. Am J Transplant 2016;16:850-859.

11. Olthoff KM, Kulik L, Samstein B, Kaminski M, Abecassis M, Emond J, et al. Validation of a current definition of early allograft dysfunction in liver transplant recipients and analysis of risk factors. Liver Transpl 2010;16:943-949.

12. Deschênes M, Belle SH, Krom RA, Zetterman RK, Lake JR. Early allograft dysfunction after liver transplantation: a definition and predictors of outcome. National Institute of Diabetes and Digestive and Kidney Diseases Liver Transplantation Database. Transplantation 1998;66:302-310.

13. Wagener G, Raffel B, Young AT, Minhaz M, Emond J. Predicting early allograft failure and mortality after liver transplantation: the role of the postoperative Model for End-stage Liver Disease score. Liver Transpl 2013;19:534-542.

14. Hoyer DP, Paul A, Gallinat A, Molmenti EP, Reinhardt R, Minor T, et al. Donor information based prediction of early allograft dysfunction and outcome of liver transplantation. Liver Int 2015;35:156-163.

15. Oweira H, Lahdou I, Daniel V, Opelz G, Schmidt J, Zidan A, et al. Early postoperative acute phase response in patients with early graft dysfunction is predictive of 6-month and 12-month mortality in liver transplant recipients. Human Immunology 2016;77:952-960.

16. Curry MP, Forns X, Chung RT, Terrault NA, Brown R Jr, Fenkel JM, et al. Sofosbuvir and ribavirin prevent recurrence of HCV infection after liver transplantation: an open-label study. Gastroenterology 2015;148:100-107.

17. Donato MF, Morelli C, Romagnoli R, Invernizzi F, Mazzarelli C, lemmolo RM, et al. Prevention of hepatitis $\mathrm{C}$ recurrence by bridging sofosbuvir/ribavirin from pre to 
post liver transplant: a real life strategy. Liver Int 2016, doi: 10.1111/liv.13322. [Epub ahead of print].

18. Tapper EB, Hughes MS, Buti M, Dufour J-F, Flamm S, Firdoos S, et al. The optimal timing of hepatitis $C$ therapy in transplant eligible patients with Child $B$ and $C$ cirrhosis: a cost-effectiveness analysis. Transplantation 2016, 10.1097/TP.0000000000001400. [Epub ahead of print].

19. Charlton M, Everson GT, Flamm SL, Kumar P, Landis C, Brown RS Jr, et al. Ledipasvir and sofosbuvir plus ribavirin for treatment of HCV infection in patients with advanced liver disease. Gastroenterology 2015;149:649-659.

20. Manns M, Samuel D, Gane JE, Mutimer D, McCaughan G, Buti M, et al. Ledipasvir and sofosbuvir plus ribavirin in patients with genotype 1 or 4 hepatitis $C$ virus infection and advanced liver disease: a multicentre, open-label, randomised, phase 2 trial. Lancet Infect Dis 2016;16:685-697.

21. Cheung MCM, Walker AJ, Hudson BE, Verma S, McLauchlan J, Mutimer DJ, et al. Outcomes after successful direct-acting antiviral therapy for patients with chronic hepatitis C and decompensated cirrhosis. J Hepatol 2016;65:741-747.

22. Foster FR, Irving WL, Cheung MC, Waljer AJ, Hudson BE, Verma S, et al. Impact of direct acting antiviral therapy in patients with chronic hepatitis $\mathrm{C}$ and decompensated cirrhosis. J Hepatol 2016;64:1224-1231.

23. Vinaixa C, Coilly A, Belli LS, Mix H, Duvoux C, Berenguer M. Safety and efficacy of interferon-free antiviral treatment in hepatitis $C$ patients with MELD score 20 and over [abstract]. Hepatology 2016;64(Suppl):986A.

24.Levitsky J, Verna EC, O'Leary JG; Bzowej NH, Moonka DK, Hyland RH, et al. Perioperative ledipasvir-sofosbuvir for $\mathrm{HCV}$ in liver-transplant recipients. N Engl $\mathrm{J}$ Med. 2016;375(21):2106-8. 
25. Peralta C, Jiménez-Castro MB, Gracia-Sancho J. Hepatic ischemia and reperfusion injury: effects on the liver sinusoidal milieu. J Hepatol 2013;59:1094-1106.

26. Garcia-Retortillo M, Forns X, Feliu A, Moitinho E, Costa J, Navasa M, et al. Hepatitis C virus kinetics during and immediately after liver transplantation. Hepatology 2002;35:680-687.

27. Fukumoto T, Berg T, Ku Y, Bechstein WO, Knoop M, Lemmens HP, et al. Viral dynamics of hepatitis $\mathrm{C}$ early after orthotopic liver transplantation: evidence for rapid turnover of serum virions. Hepatology 1996;24:1351-1354.

28. Charlton M. Liver biopsy, viral kinetics, and the impact of viremia on severity of hepatitis C virus recurrence. Liver Transpl 2003;9:S58-S62.

29. European Association for the Study of the Liver. EASL clinical practice guidelines: liver transplantation. J Hepatol 2016;64:433-485. 
Table 1. Recipient and donor characteristics.

Study population $(n=603)$

Recipient features

Age (years)

$55.8[50.6-61.2]$

Male gender

487 (80.8\%)

Body Mass Index $\left(\mathrm{Kg} / \mathrm{m}^{2}\right)$

25 [23-27]

Hepatocellular carcinoma

322 (53.4\%)

MELD at LT

$15[11-19]$

HCV RNA negative at LT

$77(12.8 \%)$

Donor features

Age (years)

$63.0[50.7-72.3]$

Male gender

$341(56.6 \%)$

Body Mass Index $\left(\mathrm{Kg} / \mathrm{m}^{2}\right)$

25 [23-28]

Body Mass Index $\geq 30 \mathrm{Kg} / \mathrm{m}^{2}$

$71(11.8 \%)$

Cause of brain death

Cerebrovascular

$436(72.3 \%)$

Trauma

$106(17.6 \%)$

Anoxia

$50(8.3 \%)$

Other

$11(1.8 \%)$ 
HBcAb positivity

Donor Risk Index

Macrovesicular steatosis $\geq 30 \%$ *
$69(11.4 \%)$

$1.8[1.5-2.1]$

$18(3.0 \%)$

Donor-Recipient match

Donor age x Recipient MELD

901 [625-1219]

Transplant times

Cold ischemia time (min)

469 [401-539]

Cold Ischemia time $\geq 8$ hours

$280(46.4 \%)$

Warm ischemia time (min)

23 [20-28]

90-day outcomes

Graft loss

$35(5.8 \%)$

Retransplantation

$20(3.3 \%)$

Patient death

$18(3.0 \%)$

Numerical variables: median [Q1-Q3]; categorical variables: numbers (prevalence, \%).

*3 missing.

Abbreviations: HBcAb, hepatitis B core antibody; LT, liver transplantation; MELD, Model for End-stage Liver Disease. 
Table 2. Comparison of the different EAD definitions.

\begin{tabular}{|c|c|c|c|}
\hline & Olthoff ${ }^{\#}$ & $\begin{array}{c}\text { Bilirubin } \\
>10 \mathrm{mg} / \mathrm{dL} \\
\text { on days } 2 \text { to } 7\end{array}$ & $\begin{array}{c}\text { MELD } \geq 19 \\
\text { on day } 5\end{array}$ \\
\hline EAD rate & $328 / 603$ (54.4\%) & $308 / 601^{\wedge}(51.2 \%)$ & $314 / 599 *(52.4 \%)$ \\
\hline Graft loss 90-day, EAD vs no & & & \\
\hline EAD & $9.8 \%$ vs $1.1 \%$ & $8.4 \%$ vs $2.4 \%$ & $9.2 \%$ vs $0.7 \%$ \\
\hline Sensitivity $(95 \% \mathrm{Cl})$ & $0.9-(0.8-1.0)$ & $0.8(0.6-0.9)$ & $0.9(0.8-1.0)$ \\
\hline Specificity (95\% Cl) & $0.5(0.4-0.5)$ & $0.5(0.5-0.5)$ & $0.5(0.5-0.5)$ \\
\hline Positive predictive value $(95 \% \mathrm{Cl})$ & $0.01(0.002-0.03)$ & $0.02(0.01-0.05)$ & $0.01(0.001-0.03)$ \\
\hline Negative predictive value $(95 \% \mathrm{Cl})$ & $0.9(1.0-0.9)$ & $0.9(1.0-0.9)$ & $0.9(0.9-0.9)$ \\
\hline Positive likelihood ratio & 1.8 & 1.6 & 1.9 \\
\hline Negative likelihood ratio & 0.2 & 0.4 & 0.1 \\
\hline
\end{tabular}

\footnotetext{
\#Total bilirubin $\geq 10 \mathrm{mg} / \mathrm{dL}$ or INR $\geq 1.6$ on postoperative day 7 or AST or ALT $>2000$ IU/L within the first 7 days after transplant.

$\wedge 2$ patients lost their graft on day 1 after transplant.

*4 patients lost their graft within day 4 after transplant.

Abbreviations: $\mathrm{Cl}$, confidence interval; EAD, early allograft dysfunction; MELD, Model for End-stage Liver Disease.
} 
Table 3. Differences between EAD and non-EAD recipients at univariate analysis. EAD defined as MELD $\geq 19$ on day 5 post-transplant.

\begin{tabular}{|c|c|c|c|}
\hline & $\begin{array}{c}\text { EAD } \\
(n=314)\end{array}$ & $\begin{array}{l}\text { No EAD } \\
(n=285)\end{array}$ & $\mathbf{p}$ \\
\hline \multicolumn{4}{|l|}{ Recipient features } \\
\hline Age (years) & $55.4[49.5-60.7]$ & $56.0[50.9-61.4]$ & 0.23 \\
\hline Male gender & $259(82.5 \%)$ & $224(78.6 \%)$ & 0.23 \\
\hline Body Mass Index $\left(\mathrm{Kg} / \mathrm{m}^{2}\right)$ & 25 [23-27] & 25 [23-27] & 0.24 \\
\hline Hepatocellular carcinoma & $136(43.3 \%)$ & $183(64.2 \%)$ & $<0.001$ \\
\hline MELD at LT & 17 [13-22] & $13[9-17]$ & $<0.001$ \\
\hline$<15$ & $102(32.5 \%)$ & $179(62.8 \%)$ & \\
\hline $15-25$ & $156(49.7 \%)$ & 89 (31.2\%) & $<0.001$ \\
\hline$>25$ & $56(17.8 \%)$ & $17(6.0 \%)$ & \\
\hline HCV RNA negative at LT & $19(6.1 \%)$ & $57(20.0 \%)$ & $<0.001$ \\
\hline \multicolumn{4}{|l|}{ Donor features } \\
\hline Age (years) & 63.6 [51.9-72.8] & 62.2 [49.3-71.8] & 0.40 \\
\hline$<50$ & $67(21.3 \%)$ & $74(26.0 \%)$ & \\
\hline $50-70$ & $141(44.9 \%)$ & 124 (43.5\%) & 0.39 \\
\hline$>70$ & $106(33.8 \%)$ & 87 (30.5\%) & \\
\hline Male gender & $172(54.8 \%)$ & $165(57.9 \%)$ & 0.44 \\
\hline
\end{tabular}




\section{Cause of brain death}

Cerebrovascular

Trauma

Anoxia

Other

Body Mass Index $\left(\mathrm{Kg} / \mathrm{m}^{2}\right)$

Body Mass Index $\geq 30 \mathrm{Kg} / \mathrm{m}^{2}$

Donor Risk Index

HBcAb positive

Macrovesicular steatosis $\geq 30 \%$
$235(74.8 \%)$

$56(17.8 \%)$

$18(5.8 \%)$

$5(1.6 \%)$

25 [23-28]

$39(12.4 \%)$

$1.8[1.6-2.1]$

$41(13.0 \%)$

$10(3.2 \%)^{*}$
$198(69.5 \%)$

$50(17.5 \%)$

$32(11.2 \%)$

$5(1.8 \%)$

25 [23-29]

0.47

$1.8[1.5-2.0]$

0.003

$27(9.5 \%)$

0.17

$4(1.4 \%)^{\#}$

0.15

\section{Donor-Recipient match}

Donor age x Recipient MELD

$<0.001$

\section{Transplant times}

Cold ischemia time (min)

Cold Ischemia Time $\geq 8$ hours

Warm ischemia time (min)
492 [420-562]

449 [383-512]

$<0.001$

$174(55.4 \%)$

$105(36.8 \%)$

$<0.001$

23 [20-28]

23 [20-27]

0.78

\section{Outcomes}

Hospitalization (days)

Intensive care unit (days)
16 [12-26]

$11[9-16]$

$<0.001$

$4[2-8]$

$3[2-4]$ $<0.001$ 
Graft loss within 90 days

Re-LT within 90 days

Patient death within 90 days

\section{Liver transplant era}

Nov 2002-Mar 2009 ( $n=300)$

Apr 2009-Jun 2016 ( $n=299)$
$29(9.2 \%)$

$2(0.7 \%)$

$<0.001$

$15(4.8 \%)$

$1(0.4 \%)$

$<0.001$

$16(5.1 \%)$

$1(0.4 \%)$

$<0.001$

Numerical variables: median [Q1-Q3]; categorical variables: numbers (prevalence, \%).

${ }^{*} 2$ and ${ }^{\# 1}$ missing.

Abbreviations: $E A D$, early allograft dysfunction; $H B c A b$, hepatitis $B$ core antibody; $L T$, liver transplantation; MELD, Model for End-stage Liver Disease. 
Table 4. Recipient and donor characteristics according to HCV RNA status at liver transplant.

HCV RNA Positive

$(n=523)$
HCV RNA Negative

$(n=76)$

p

Recipient features

Hepatocellular carcinoma

269 (51.4\%)

$50(65.8 \%)$

0.02

MELD at LT

$<15$

$15-25$

$15[11-20]$

$231(44.2 \%)$

12 [8-17]

$<0.001$

$225(43.0 \%)$

$50(65.8 \%)$

$67(12.8 \%)$

$20(26.3 \%)$

0.002

$>25$

$293(56.0 \%)$

$230(44.0 \%)$

$6(7.9 \%)$

70 (92.1\%)

$<0.001$

2 Apr 2009-Jun 2016

\section{Donor features}

Age (years)
$<50$
$50-70$
$>70$

62.7 [50.4-71.8]

66.4 [52.8-76.2]

0.03

$127(24.3 \%)$

$14(18.4 \%)$

233 (44.6\%)

$30(39.5 \%)$

0.15

$163(31.1 \%)$

$32(42.1 \%)$

Donor Risk Index

1.8 [1.5-2.1]

1.9 [1.6-2.1]

0.45

HBcAb positivity

$60(11.5 \%)$

$8(10.5 \%)$

0.81

Macrovesicular steatosis $\geq 30 \%$

$9(1.7 \%)^{*}$

$5(6.6 \%)$

0.01

\section{Donor-Recipient match}

Donor age x Recipient MELD

931 [638-1252]

769 [544-1010]

0.01

D-MELD >1750

$37(7.1 \%)$

$4(5.3 \%)$

0.56

Transplant features

Cold Ischemia Time (min)

Cold Ischemia Time $\geq 8$ hours

Early allograft dysfunction

(MELD $\geq 19$ Day 5 post-LT)

Graft loss within 90 days
478 [406-549]

$259(49.5 \%)$

$296(56.6 \%)$

$27(5.2 \%)$
429 [371-482]

$<0.001$

$20(26.3 \%)$

$<0.001$

19 (25.0\%)

$<0.001$

$4(5.3 \%)$

0.97 
Re-LT within 90 days

$13(2.5 \%)$

$3(3.9 \%)$

0.46

Patient death within 90 days

$14(2.7 \%)$

$3(3.9 \%)$

0.53

Numerical variables: median [Q1-Q3]; categorical variables: number (prevalence, \%)

*3 missing

Abbreviations: HBcAb, hepatitis B core positive antibody; LT, liver transplantation; MELD, model for end-stage liver disease. 
Table 5. EAD predictors at multivariate logistic regression. EAD defined as MELD $\geq 19$ on day 5 post-transplant.

\begin{tabular}{|c|c|c|c|}
\hline Risk factor & Odds Ratio & $95 \% \mathrm{Cl}$ & p \\
\hline MELD score at LT >25* & 7.4 & 4.0-14.3 & $<0.001$ \\
\hline MELD score at LT $15-25^{\star}$ & 3.2 & $2.2-4.8$ & $<0.001$ \\
\hline HCV RNA positive at LT^ & 2.7 & $1.5-5.1$ & 0.002 \\
\hline Donor age $>70$ years & 2.0 & $1.2-3.3$ & 0.01 \\
\hline Macrovesicular steatosis $\geq 30 \%$ & 6.7 & $1.9-29.1$ & 0.01 \\
\hline Cold ischemia time $\geq 8$ hours & 1.8 & $1.2-2.5$ & 0.003 \\
\hline Earlier transplant era & 1.8 & $1.2-2.7$ & 0.003 \\
\hline
\end{tabular}

${ }^{*}$ MELD score $<15$ as reference.

${ }^{\wedge}$ Donor age $<50$ years as reference.

Abbreviations: $\mathrm{Cl}$, confidence interval; EAD, early allograft dysfunction; LT, liver transplantation; MELD, Model for End-stage Liver Disease. 